\title{
Comparison of Risk Factors Related to Survival in Breast Cancer Patients in The Low and High Plains in West Sumatra, Indonesia
}

\author{
Rima Semiarty ${ }^{1}$, Rosfita Rasyid ${ }^{2}$, Daan Khambri ${ }^{3}$, Ricvan Dana Nindrea ${ }^{4}$, Cimi Ilmiawati ${ }^{5}$ \\ \{rimamenkher@yahoo.com ${ }^{1}$, rosfitarasyid135ros@gmail.com², daan_khambri@yahoo.com ${ }^{3}$, \\ ricvandana7@gmail.com $\left.{ }^{4}\right\}$ \\ Department of Public Health and Community Medicine, Faculty of Medicine Universitas Andalas, \\ Padang, Indonesia ${ }^{1,2,4}$ \\ Department of Surgical Oncology, Faculty of Medicine Universitas Andalas, \\ Padang, Indonesia ${ }^{3}$ \\ Doctoral Program, Faculty of Medicine, Public Health and Nursing Universitas Gadjah Mada, \\ Yogyakarta, Indonesia ${ }^{4}$ \\ Department of Environmental and Preventive Medicine, Jichi Medical School of Medicine, Japan ${ }^{5}$
}

\begin{abstract}
Breast cancer continues to be a major cause of morbidity among women in Indonesia. Possible effects of etiological risk factors on breast cancer specific survival (BCSS) of the disease is not clear especially to compare risk factors in the low and high plains. This study was designed to explore the comparison of risk factor related to survival in breast cancer patients in the low and high plains in West Sumatera, Indonesia. Data were extracted from medical records of Dr M Djamil General Hospital Padang in 2007 until 2016 for all breast cancer patients treated with a 219 patients. Disease free survival and overall survival rates and their relationship with low and high plains residence were investigated using survival analysis (the Kaplan-Meier method and log rank test) and risk factors related to survival in breast cancer patients using chi-square test. Data were analyzed using the STATA program. Disease free survival in breast cancer patients in the low plains was 54 months (95\% CI 45-63) lower than high plains 63 months (95\% CI 5472). Overall survival rate revealed median survival of 57 months (95\% CI 49-64) in low plains lower than high plains 62 months (95\% CI 53-72). The log-rank test $\mathrm{p}$ value was < 0.05 indicated that patients in the low plains are significantly increasing recurrence and mortality. Risk factors for breast cancer in low plains residence are advance stage, obesity and family history of breast cancer while in high plains residence are advance stage, lowlevel education, work, and obesity $(\mathrm{p}<0.05)$. Stage had the highest hazard ratio or dominant factor for breast cancer patients in low plains $(\mathrm{HR}=7.9$ [95\% $\mathrm{CI}=3.42-18.34])$ and high plains $(\mathrm{HR}=6.3[95 \% \mathrm{CI}=1.12-34.73])$. This analysis confirmed breast cancer patients in the low plains had low survival rate than high plains. Advance stage, obesity and family history of breast cancer associated with survival in breast cancer patients in low plains but in high plains residence are advance stage, low-level education, work, and obesity. The stage had the highest hazard ratio for breast cancer.
\end{abstract}

Keywords: Breast Cancer, Risk Factor, Low-High Plains. 


\section{Introduction}

Breast cancer ranks first of all cancer diseases in women encountered worldwide [1]. An estimated $23 \%$ or $1,383,500$ new cases a year and $14 \%$ or 458,400 cases will be end in death [2]. The United States data in 2014 estimated 232,670 new cases of breast cancer [3]. In Indonesia, there are 39,831 new cases of breast cancer every year. Hospital Information System in 2013 reports an incidence rate of 40/100,000 women. In 2009, breast cancer was the leading cause of death due to carcinoma disease hospitalized [4]. Breast cancer is a heterogeneous tumor that has various subtypes with different biological behaviors and clinicopathological and molecular characteristics [5]. In the last 20 years, there has been an increase in the understanding of multistep carcinogenesis and the leading role of genetic change in the diagnosis, treatment, and prevention of breast cancer. This leads to an increase in prevention, detection and treatment strategies for breast cancer patients.

The cause of breast cancer is multifactorial. Several risk factors for breast cancer have been known nowadays. The risk factors are differentiated into nonmodifiable risk factors: age, sex, genetic factors (5-7\%), family history of breast cancer, history of previous breast cancer and proliferative breast disease - modifiable risk factors: menstrual and reproductive factors, radiation exposure, hormone replacement therapy, alcohol, and high-fat diet. Some environmental factors include organochlorine chemicals, electromagnetic field, and smoking [6]. Breast cancer due to carcinogenesis is multifactorial, the occurrence of breast cancer in cancer patients in Southeast Asia has its risk factors that could be different from breast cancer patients in western countries. Risk factors such as smoking, alcohol, obesity, nulliparas, early menarche, hormonal drug consumption are rare in patients with breast cancer in Southeast Asia [4].

Based on previous research, it is known that around $73.25 \%$ of the most common cancers are found on the lowlands compared to the highlands. It is not yet known factors that affect the incidence of breast cancer and the type of cancer and the most common, what type of cancer is sporadic or heredity. Therefore, this study is very necessary to find the main causes of breast cancer and preventive actions. Apart from that from the population, there is no definite data because Indonesia does not have a cancer register and a good national mortality record [4].

\section{Materials and Methods}

\subsection{Study design and research sample}

This cross-sectional study was conducted Padang City from the cancer registry in Surgical Oncology Dr M Djamil General Hospital from 2012 to Augustus 2017. This study was performed on 161 breast cancer patients living in low plains and 57 in high plains.

\subsection{Operational definitions}

The variables of this study included independent variable is a stage, marital status, immunotherapy used, educational level, work status, obesity, family history of breast cancer, breastfeeding, oral contraception, chemotherapy, radiotherapy, hormonal replacement therapy and parity and the dependent variable is breast cancer. 


\subsection{Data collection technique}

Data were collected from medical records at the Division of Surgical Oncology Dr M. Djamil General Hospital in Padang. This data was then coded and analyzed.

\subsection{Data analysis}

Bivariate analysis of the data in this study was used to find the disease-free, and overall survival duration of the breast cancer patients was conducted on these survival statistics using the Kaplan-Meier method and log-rank test. Risk factors related to survival in breast cancer patients used the chi-square test. Data were analyzed by using STATA program.

\section{Results}

Tabel 1. Risk factors for breast cancer in patients living in the lowlands and highlands

\begin{tabular}{|c|c|c|c|c|c|c|c|c|}
\hline \multirow[b]{2}{*}{ Variables } & \multicolumn{4}{|c|}{ Low Plains } & \multicolumn{4}{|c|}{ High Plains } \\
\hline & $\mathrm{n}$ & $\%$ & $\begin{array}{c}P \\
\text { Value }\end{array}$ & HR $(95 \%$ CI $)$ & $\mathrm{n}$ & $\%$ & $P$ Value & $\mathrm{HR}(95 \% \mathrm{CI})$ \\
\hline \multicolumn{9}{|l|}{ Stage } \\
\hline Early & 74 & 45.96 & \multirow[t]{2}{*}{$0.000^{*}$} & 10.07 (4.43- & 20 & 35.09 & \multirow[t]{2}{*}{$0.002 *$} & \multirow[t]{2}{*}{$10.95(2.41-49.6)$} \\
\hline Advanced & 87 & 54.04 & & 22.89) & 37 & 64.91 & & \\
\hline Marital status & & & \multirow{3}{*}{0.616} & \multirow{3}{*}{$1.67(0.22-12.08)$} & & & \multirow{3}{*}{0.54} & \multirow[t]{3}{*}{$0.67(0.18-2.47)$} \\
\hline Married & 156 & 3.70 & & & 6 & 10.53 & & \\
\hline No married & 6 & 96.30 & & & 51 & 89.47 & & \\
\hline \multicolumn{9}{|l|}{ Using } \\
\hline \multicolumn{9}{|l|}{ immunotherapy } \\
\hline Yes & 2 & 1.23 & & & 0 & 0 & & \\
\hline No & 160 & 98.77 & 1.00 & $4.5(4.22-14.99)$ & 56 & 100 & N/A & N/A \\
\hline \multicolumn{9}{|l|}{ Education } \\
\hline Low & 29 & 17.90 & \multirow[t]{2}{*}{0.541} & \multirow[t]{2}{*}{$0.80(0.39-1.62)$} & 12 & 21.05 & \multirow[t]{2}{*}{$0.018 *$} & \multirow[t]{2}{*}{$0.26(0.08-0.79)$} \\
\hline High & 133 & 82.10 & & & 45 & 78.95 & & \\
\hline \multicolumn{9}{|l|}{ Work } \\
\hline No & 94 & 58.02 & \multirow[t]{2}{*}{0.84} & \multirow[t]{2}{*}{$0.94(0.52-1.69)$} & 24 & 42.11 & \multirow[t]{2}{*}{$0.032 *$} & \multirow[t]{2}{*}{$0.27(0.007-0.88)$} \\
\hline Yes & 68 & 41.98 & & & 33 & 57.89 & & \\
\hline \multicolumn{9}{|l|}{ Obesity } \\
\hline No & 95 & 58.64 & \multirow[t]{2}{*}{$0.006^{*}$} & \multirow[t]{2}{*}{$0.37(0.18-0.75)$} & 32 & 56.14 & $0.030 *$ & $0.18(0.04-0.85)$ \\
\hline Yes & 67 & 41.36 & & & 25 & 43.86 & & \\
\hline Family history & & & & & & & & \\
\hline No & 51 & 31.48 & $0.037^{*}$ & $2.24(1.04-4.82)$ & 8 & 14.04 & 1.000 & $5.69(5.55-10.55)$ \\
\hline Yes & 111 & 68.52 & & & 49 & 85.96 & & \\
\hline Breasfeeding St & & & & & & & & \\
\hline No & 27 & 16.67 & 0.11 & $0.57(0.28-1.15)$ & 5 & 8.77 & 0.829 & $0.845(0.184-3.84)$ \\
\hline Yes & 135 & 83.33 & & & 52 & 91.23 & & \\
\hline $\begin{array}{l}\text { History of } \\
\text { control pills usa }\end{array}$ & & & & & & & & \\
\hline No & 131 & 80.86 & 0.09 & $3.35(0.80-13.93)$ & 17 & 29.82 & 1.000 & $6.4(6.1-10.11)$ \\
\hline Yes & 31 & 19.14 & & & 40 & 70.18 & & \\
\hline Using Imuno & & & & & & & & \\
\hline No & 160 & 98.77 & 1.00 & $4.5(4.22-14.99)$ & 0 & 0 & N/A & N/A \\
\hline Yes & 2 & 1.23 & & & 56 & 100 & & \\
\hline Do Operation & & & & & & & & \\
\hline No & 16 & 9.94 & 0.725 & $1.20(0.42-3.36)$ & 3 & 5.36 & 0.724 & $0.668(0.086-5.455)$ \\
\hline Yes & 145 & 90.06 & & & 53 & 94.64 & & \\
\hline Do Chemothera & & & & & & & & \\
\hline
\end{tabular}




\begin{tabular}{|c|c|c|c|c|c|c|c|c|}
\hline No & 39 & 24.07 & 0.288 & $1.50(0.70-3.25)$ & 15 & 73.21 & 0.837 & $1.17(0.259-5.282)$ \\
\hline Yes & 123 & 75.93 & & & 41 & 26.79 & & \\
\hline \multicolumn{9}{|c|}{ Do Radiotherapy } \\
\hline No & 25 & 15.43 & 0.458 & $1.38(0.56-3.27)$ & 9 & 16.07 & 0.738 & $0.818(0.252-2.646)$ \\
\hline Yes & 137 & 84.57 & & & 47 & 83.93 & & \\
\hline \multicolumn{9}{|c|}{ Therapy hormone } \\
\hline No & 149 & 91.98 & 0.418 & $0.61(0.19-1.99)$ & 53 & 94.64 & 1.000 & $1.66(1.51-16.00)$ \\
\hline Yes & 13 & 8.02 & & & 3 & 5.36 & & \\
\hline \multicolumn{9}{|l|}{ Menarche } \\
\hline$<12$ tahun & 25 & 15.43 & 0.241 & $0.66(0.33-1.31)$ & 14 & 24.56 & 0.161 & $0.466(0.160-1.355)$ \\
\hline$>=12$ tahun & 137 & 84.57 & & & 43 & 75.44 & & \\
\hline \multicolumn{9}{|l|}{ Parity } \\
\hline Low & 53 & 32.72 & 0.945 & $1.02(0.55-1.88)$ & 25 & 43.86 & 0.130 & $0.428(0.130-1.41)$ \\
\hline High & 109 & 67.28 & & & 32 & 56.14 & & \\
\hline
\end{tabular}

Table 1 known risk factors for breast cancer in low plains residence are an advanced stage, obesity and family history of breast cancer while in high plains residence are the advanced stage, low-level education, work, and obesity ( $\mathrm{p}<0.05)$. Stage had the highest hazard ratio or dominant factor for breast cancer patients in low plains $(\mathrm{HR}=10.07$ [95\% CI=4.43-22.89]) and high plains $(\mathrm{HR}=10.95[95 \% \mathrm{CI}=2.41-49.6])$.

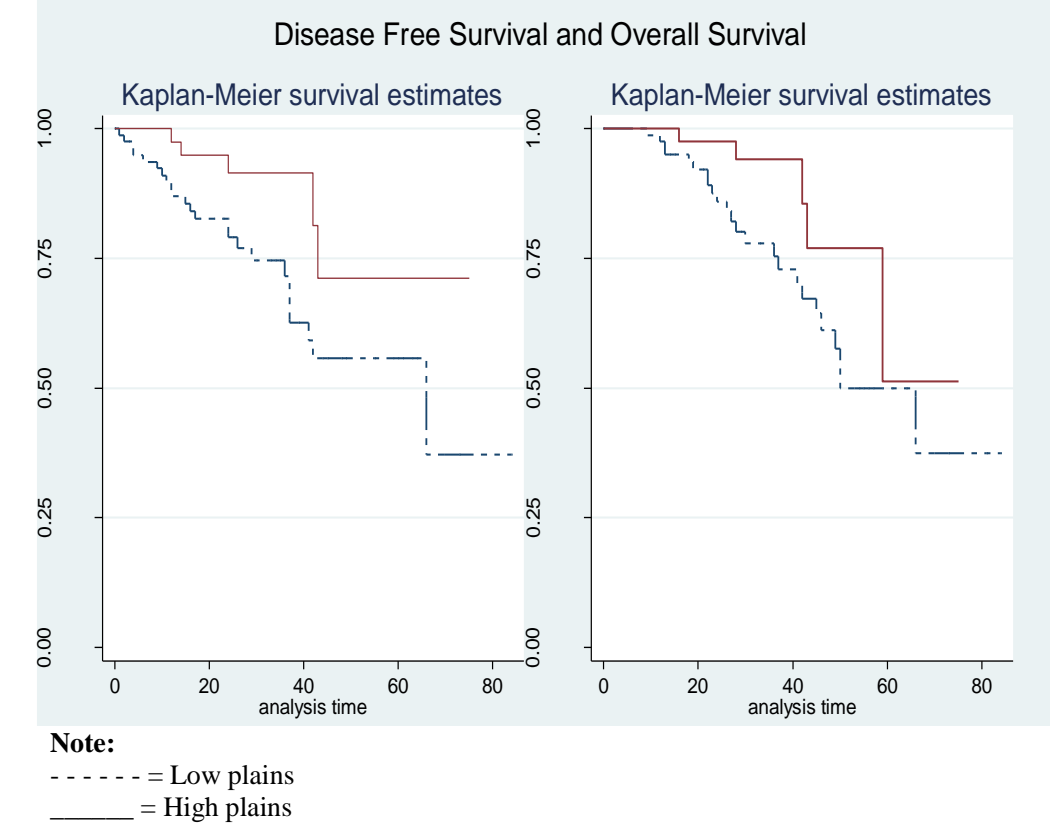

Fig. 1. Disease-Free Survival and Overall Survival.

Table 2. Disease-free survival and overall survival in breast cancer patients in the low and high plains

\begin{tabular}{|c|c|c|c|c|c|c|c|}
\hline & & Event & Censoring & $\begin{array}{c}\text { Hazard } \\
\text { Ratio }\end{array}$ & $\begin{array}{l}\text { Median } \\
\text { Follow }\end{array}$ & $95 \% \mathrm{CI}$ & $\begin{array}{l}\mathrm{P} \text { value (Log- } \\
\text { rank test) }\end{array}$ \\
\hline \multirow{2}{*}{$\begin{array}{l}\text { Disease } \\
\text { Survival }\end{array}$} & Low plains & 24 & 137 & 2,6 & 54 & $45-63$ & $0,048 *$ \\
\hline & High Plains & 5 & 51 & & 63 & $54-72$ & \\
\hline
\end{tabular}




\begin{tabular}{llllllll} 
Overall & Low plains & 24 & 137 & 2,4 & 57 & $49-64$ & 0,073 \\
Survival & High Plains & 5 & 51 & & 62 & $53-72$ & \\
& H & & & & 62 & \\
\hline
\end{tabular}

Disease-free survival in breast cancer patients in the low plains was 54 months (95\% CI 45-63) lower than high plains 63 months (95\% CI 54-72). Overall survival rate revealed median survival of 57 months (95\% CI 49-64) in low plains lower than high plains 62 months (95\% CI 53-72). There is a significant association for relapse of breast cancer patients between low plains and high plains $(\mathrm{p}<0.05)$.

\section{Discussion}

Risk factors for breast cancer in low plains residence are the advanced stage, obesity and family history of breast cancer while in high plains residence are an advanced stage, low-level education, work, and obesity $(\mathrm{p}<0.05)$. Stage had the highest hazard ratio or dominant factor for breast cancer patients in low plains $(\mathrm{HR}=10.07$ [95\% CI=4.43-22.89]) and high plains $(\mathrm{HR}=$ $10.95[95 \% \mathrm{CI}=2.41-49.6])$.

Disease-free survival in breast cancer patients in the low plains was 54 months $(95 \% \mathrm{CI}$ 45-63) lower than high plains 63 months (95\% CI 54-72). Overall survival rate revealed median survival of 57 months (95\% CI 49-64) in low plains lower than high plains 62 months (95\% CI 53-72). There is a significant association for relapse of breast cancer patients between low plains and high plains $(\mathrm{p}<0.05)$.

Based on the results obtained that both in the lowlands and highlands, most respondents are in the early stages. According to the classification of the American Joint Committee on Cancer (AJCC) clinical stage until IIIB is the stage level in patients with breast cancer who have no metastasis to other body organs while stage IV is the stage level in patients with breast cancer that has been further characterized by metastasis found in another organ. Judging from the results of the study that both in the lowland early stages will be able to maintain its life 5 times greater than patients who are in the final stage, while in the highlands the initial stage will be able to maintain its life 6 times greater than patients who are in the final stage. Statistically, there are differences in stage levels with the survival of breast cancer patients. The risk in patients with advanced stage cancer (IV) is 1.84 times compared to the initial stage (0-III) [7].

Some families have a higher risk of suffering from certain cancers when compared to other families. The risk of a woman developing breast cancer increases 1.5-3 times if her mother or sister has breast cancer. This is in line with research conducted that low land that someone who has no history of cancer in grandmother will be able to maintain life by 4 times compared to someone who has a history of cancer in the family. Statistically, there is a difference between the status of the presence of a history of cancer in the family and the survival of patients with breast cancer. However, this does not happen to people who live in the highlands, that the history of breast cancer in the family is not a factor that affects survival [7],[8].

Judging from the existence of a history of cancer in children that someone who has no history of cancer in children will be able to maintain life by 6 times compared to someone who has a history of cancer in children. Statistically, there is no difference between the status of the presence of a history of cancer in children with the survival of patients with breast cancer. This is in line with research that patients with a first-degree family history (mother and siblings) have a 4-6 times higher risk than women who do not have this risk factor. Patients with premenopausal first-degree families who have bilateral breast cancer have a risk of 9 times. Patients 
with postmenopausal first-degree families who have bilateral breast cancer have a 4-5.4 times risk [9].

\section{References}

[1] Torre LA, Bray F, Siegel RL, et al. Global cancer statistics, 2012. CA Cancer J Clin. 2015; 65: 87-108.

[2] Jemal A, Bray F, Ferlay J, et al. Global cancer statistics. CA Cancer J Clin. 2011; 61: 69-90.

[3] Siegel R, Ma J, Zou Z, Jemal A. Cancer statistics, 2014. CA Cancer J Clin. 2014; 64: 9-29.

[4] Harahap WA, Ramadhan, Khambri D, et al. Outcomes of trastuzumab therapy for 6 and 12 months in Indonesian national health insurance system clients with operable HER2-positive breast cancer. Asian Pac J Cancer Prev. 2017; 18: 1151-7.

[5] Carey LA, Perou CM, Livasy CA, et al. Race, breast cancer subtypes, and survival in the carolina breast cancer study. JAMA. 2006; 295: 2492-502.

[6] Clemons M, Goss P. Estrogen and the risk of breast cancer. N Engl J Med. 2001; 344: 276-85.

[7] Tas'ady R, Fanany I, Fanany R. Sickness ruins the complexion, breeding disappears without gold: culture and the interpretation of illness among the Minangkabau of West Sumatra, Indonesia. International Journal of Health, Wellness \& Society. 2012; 2(4): 31-41.

[8] Wildeman MA, Fles R, Herdini C, Indrasari RS, Vincent AD, Tjokronagoro M, et al. Primary treatment results of nasopharyngeal carcinoma (NPC) in Yogyakarta, Indonesia. PLoS one. 2013; 8(5): e63706

[9] Pramono L, Setiati S, Soewondo P, Subekti I, Adisasmita A, Kodim N, Sutrisna B. Prevalence and Predictors of Undiagnosed Diabetes Mellitus in Indonesia. Age. 2010; 42(4): 216-223 